ISSN : 2395-647X Vol. 4, No. 3, September 2018

International Journal of Geology and Earth Sciences

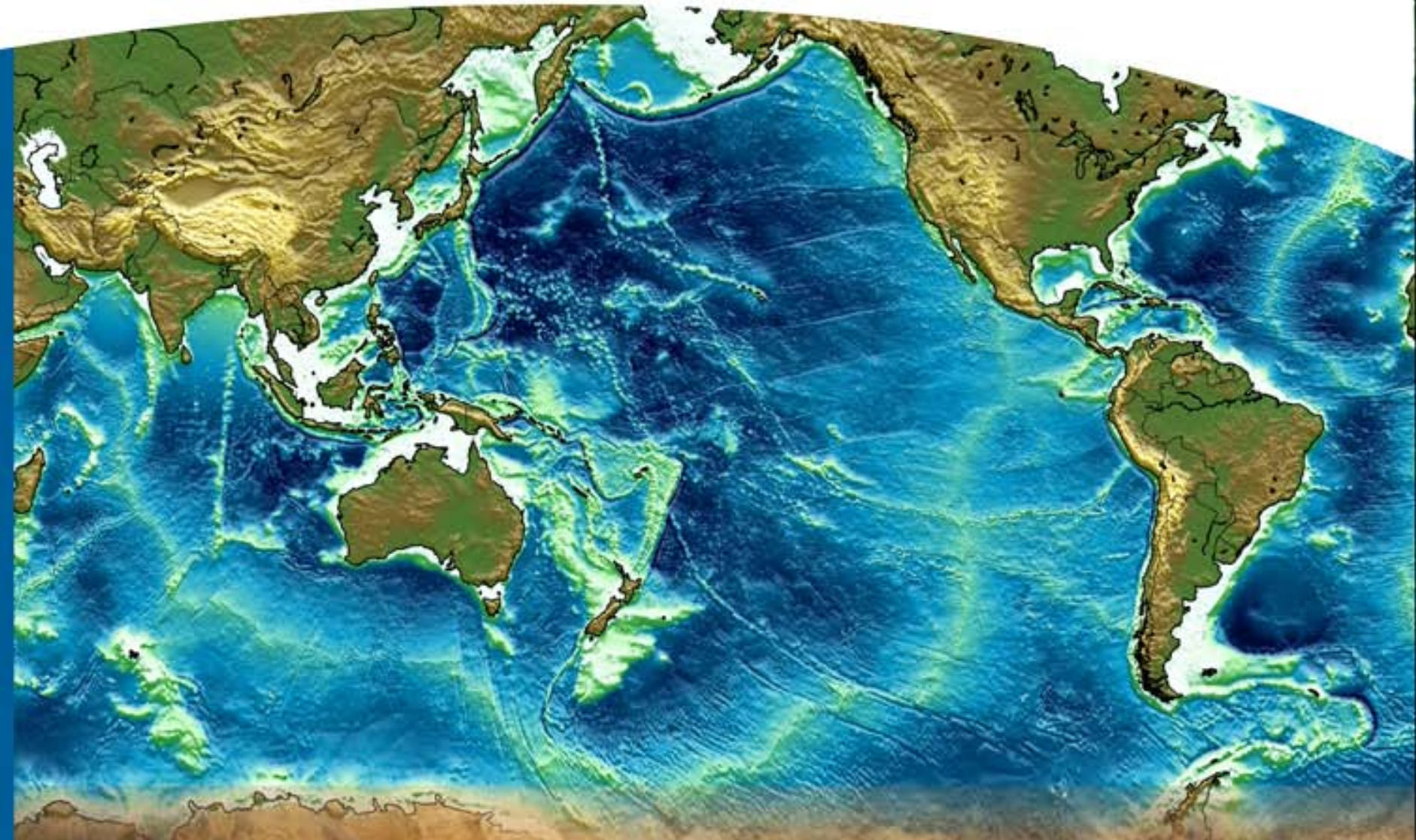

3

Email : info.ijges@gmail.com or editor@ijges.com 


\title{
TILT DERIVATIVE TECHNIQUE-MAGNETIC ANALYSIS FOR DELINEATION OF SUBSURFACE FEATURES, ANANTAPUR DISTRICT, ANDHRA PRADESH
}

\author{
M Preeti ${ }^{1 *}$ and G Ramadass ${ }^{2}$ \\ *Corresponding Author: M Preeti $₫$ preeti, vision@gmail.com
}

Received on: $13^{\text {th }}$ July, 2018 https://doi.org/10.32937/IJGES.4.3.2018.38-41 Accepted on: $25^{\text {th }}$ August, 2018

Magnetic method is the simplest method to identify the geological features which are prevailing in the subsurface. The study area is located in western part of the Cuddapah Basin which mainly comprised Tadipatri shales and sills. Tilt derivative technique is used to delineate the faults and hidden sills in the subsurface and constructed a structural map. There are twenty faults are identified in this area which are trending mainly in two directions NW-SE and NE-SW. The hidden sill segments are the source for high magnetic anomalies in the middle part of the study area and these segments also trending in same direction as sill outcrops in the northern part.

Keywords: Tadipatri shales, Hidden sills, Sill outcrops, Faults, Sill segments

\section{INTRODUCTION}

The study area covered about $20 \mathrm{~km}^{2}$, located in Putluru and Yellanuru mandals, Ananthapur district, Andhra Pradesh. This area is situated between latitudes $14^{\circ} 45^{\prime}-14^{\circ} 50^{\prime} \mathrm{N}$ and longitudes $77^{\circ} 55^{\prime}-78^{\circ} 05^{\prime} \mathrm{E}$. This area is totally covered with agricultural fields. The prime objective of the present study is to identify the presence of sills, dykes, faults and fractures in the subsurface stratum. To identify these features, the magnetic studies and its tilt derivative filter were applied.

\section{GEOLOGY}

The study area situated in the intra cratonic
Proterozoic Cuddapah Basin which occupies an very important place in Indian geology. Tadipatri shales of Chitravati group are the main geological formations in this area. Based on geology, volcanic rocks like dykes and sills intruded into Vempalle limestones and Tadipatri shales. This igneous activity is restricted to the southwestern margin of the Cuddapah basin and The present study area also present in this region (Murty, 1964; Sen and Narasimha Rao, 1967; King, 1872; and Nagaraja Rao et al., 1987).

The sills are present in the western side and in the northern part of the survey area as out crops. These sills are consist of metapyroxenite

Research Scholar, Department of Geophysics, Osmania University, Hyderabad, India.

Professor (Retd.,), Department of Geophysics, Osmania University, Hyderabad, India. 
and metagabbro. A fault can be seen in NW direction lies in the middle of the study area (GSI, 2001).

\section{MAGNETIC DATA ANALYSIS}

Magnetic measurement were carried out along four traverses $\mathrm{T} 1-\mathrm{T} 4$, about $4 \mathrm{~km}$ long and station intervals of $25 \mathrm{~m}$. These are oriented in the NNE trending perpendicular to major Fault in this area. These are not equally spaced because of inaccessibility. Diurnal corrected Total magnetic Intensity colour contour map (Figure 1) is prepared with a contour interval of $20 \mathrm{nT}$. The magnetic anomaly ranges are from $40898 \mathrm{nT}$ to $42215 \mathrm{nT}$.

The magnetic images are show high and low magnetic anomalies correspond to susceptibility contrast of the geological features. In this map low magnetic anomalies are noticed in the east

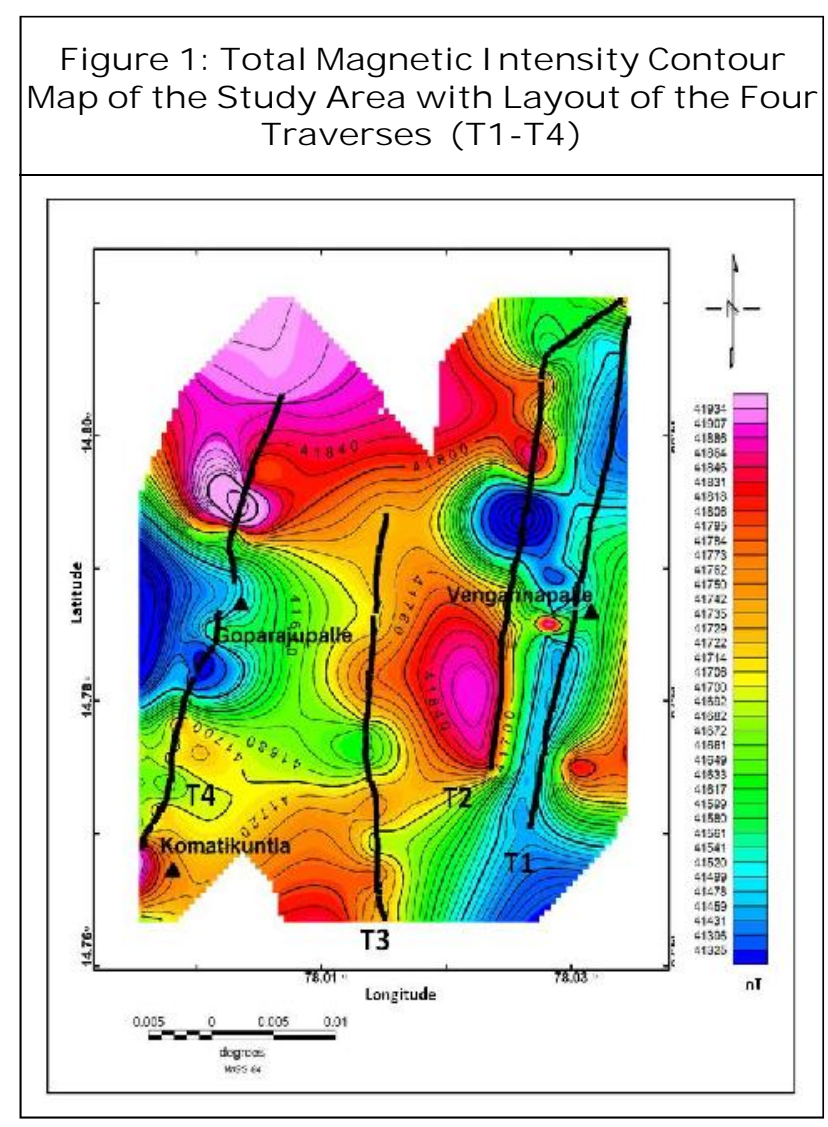

and west due to shales and highs are observed in the north due to exposed sills. In the middle part also show high anomalies infers the presence of high magnetic bodies, concealed sills in the subsurface.

\section{TI LT DERI VATI VE CONTOUR MAP}

Generally the total magnetic field strength and depth of source body effects the magnetic anomaly amplitudes and the lower amplitude anomalies may be suppressed at the expense of higher amplitudes (Oruc and Keskinsezer, 2008). To derive the clear picture of the subsurface geological features which cause these anomalies the edge detection filter, tilt derivative technique is most useful tool without diminishing the longwavelength information.

Tilt derivative is the ratio of the vertical derivative and the horizontal derivative and tilt derivative is:

$$
\theta=\tan ^{-1} \frac{\partial f / \partial z}{\partial f / \partial h}
$$

where $\partial \mathrm{f} / \partial \mathrm{z}$ and $\partial \mathrm{f} / \partial \mathrm{h}$ are the first vertical and horizontal derivatives, of the Total magnetic Intensity (Miller et al., 1994; and Verduzco et al., 2004).

The tilt angle is confined to lie between $+90^{\circ}$ and $-90^{\circ}$ regardless of the amplitudes of the vertical and horizontal derivatives. The tilt angle values are positive over the sources, zero at edges of source and is negative outside the source region (Salem et al., 2007). This technique is insensitive to the depth of the source and resolve shallow and deep sources equally well (Mita Rajaram, 2009).

Based on geology map study area is covered with shales shows low values in the tilt derivative

This article can be downloaded from http://www.ijges.com/current-issue.php 


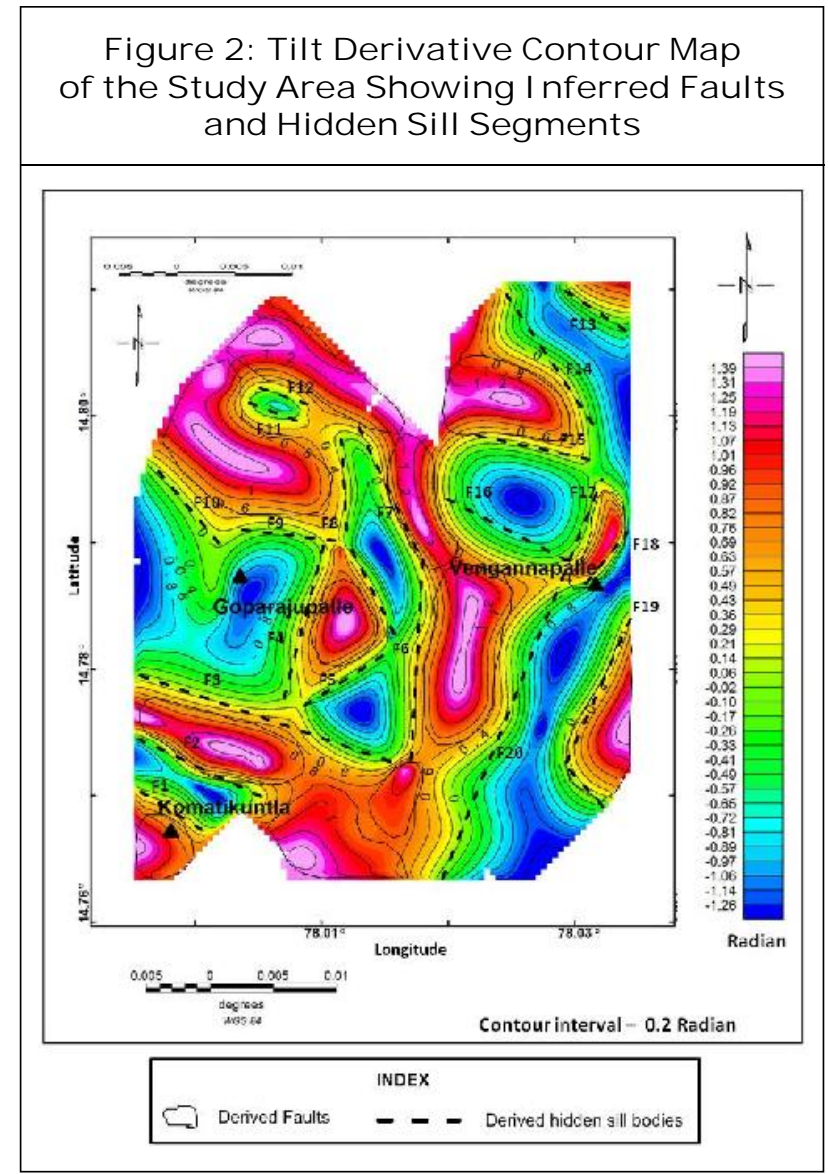

contour map (Figure 2) and sill outcrops are present in the north shows high values. But in the middle of the study area also show high values infers the presence of sill segments in the subsurface (as per geology sills or dykes are intruded in the shales) which are marked as hidden sills. The zero tilt derivative contours coincide with contacts between shales and sill segments and these may in turn represent faults in the area. These hidden sill segments and the derived faults (F1-F20) are overlaid on the geology map and prepared a structural map of the study area (Figure 3).

\section{CONCLUSI ON}

From the tilt derivative technique the edges of the high magnetic sources marked as outline of the sill segments and the inferred faults (F1-F20) which are separate the shale and sill formations show the subsurface structural pattern prevailing in the study area. It is clearly visible in this map

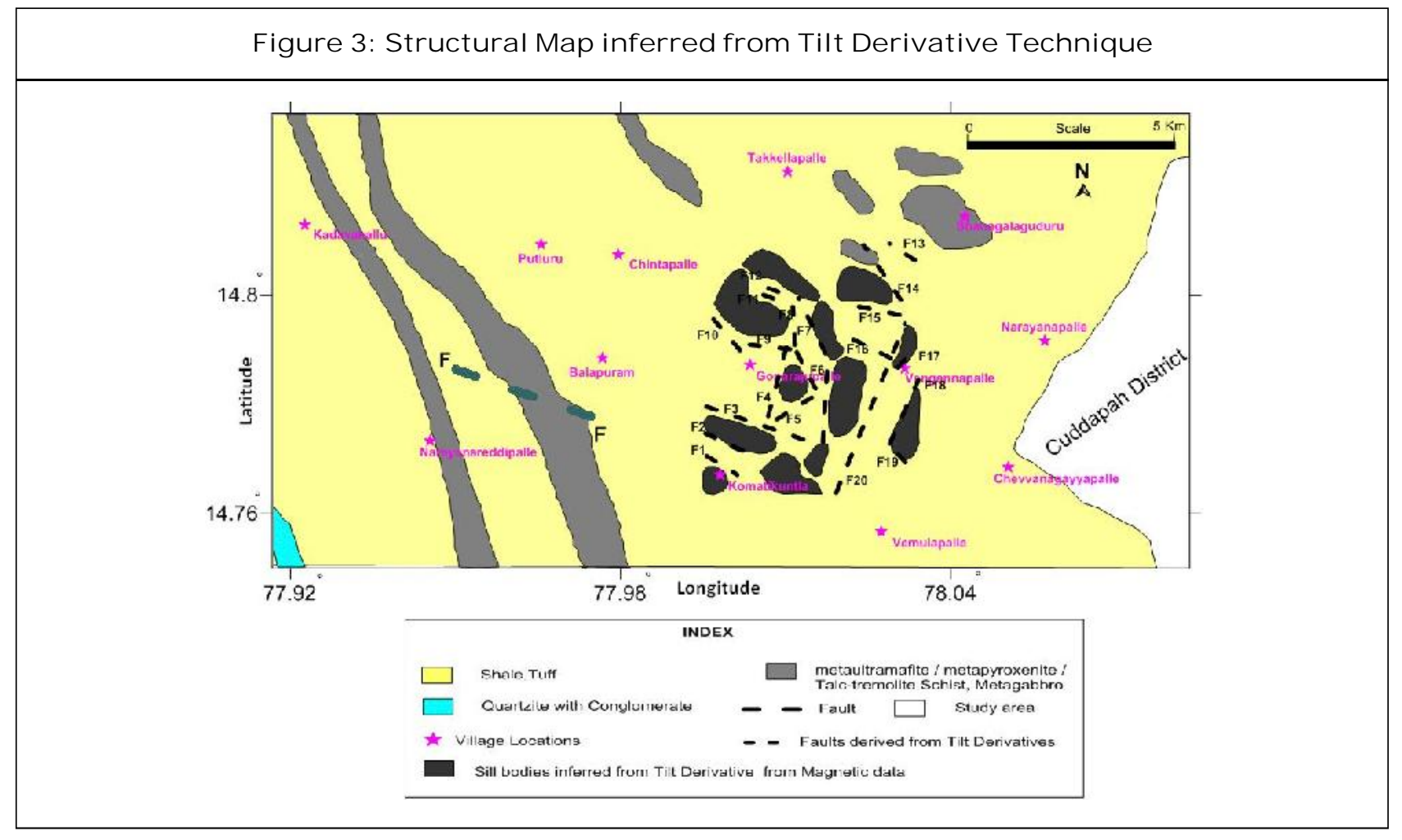

This article can be downloaded from http://www.ijges.com/current-issue.php 
(Figure 3) that multiple faults/fractures are present and these might be result sills into sill segments. The maximum faults are trending NW-SE, parrallal to main Fault and to existing exposed sills and other are in NE-SW parallal to buried sill segments.

\section{ACKNOWLEDGMENT}

One of the author (First) is highly acknowledged to the UGC (New Delhi) for awarding UGC (RFSMS) fellowship and Prof and Head, Department of Geophysics, Osmania University, Hyderabad, India, for providing the facilities in the department.

\section{REFERENCES}

1. GSI (2001), Geological Survey of India District Mineral Resource Map of Anathapur District, AP.

2. King W (1872), "The Cuddapah and Kurnool Formations in Madras Presidency", Mem. Geol. Surv. Ind., Vol. 8, Part 1, pp. 1-346.

3. Miller H G and Singh V (1994), "Potential Field Tilt-ANew Concept for Location of Potential Field Sources", Journal of Applied Geophysics, Vol. 32, pp. 213-217.

4. Mita Rajaram (2009), "What's New in Interpretation of Magnetic Data?", GEOHORIZONS, pp. 50-51.

5. Murthy N G K (1964), "The Traps of Dolerites in Cuddapah Basin", J our. Ind. Geosci. Assn., Vol. 4, pp. 79-88.
6. Nagaraja Rao B K, Rajurkar S T, Ramalingaswamy $G$ and Ravindara Babu B (1987), "Stratigraphy, Structure and Evolution of the Cuddapah Basin", in B P Radhakrishna (Ed.), Geol. Soc. India, pp. 3386, Purana Basins of Peninsular India, Memoir 6, Bangalore.

7. Oruc B and Keskinsezer A (2008), "Structural Setting of the Northeastern Biga Peninsula (Turkey) from Tilt Derivatives of Gravity Gradient Tensors and Magnitude of Horizontal Gravity Components", P ure. Appl. Geophytes, Vol. 165, pp. 1913-1927.

8. Salem A, Williams S, Fairhead J D, Ravat D $J$ and Smith R (2007), "Tilt-Depth Method: A Simple Depth Estimation Method Using FirstOrder Magnetic Derivatives", The Leading Edge, pp. 1502-1505.

9. Sen S N and Narasimha Rao Ch (1967), "Igneous Activity in Cuddapah Basin, Adjacent Areas and Suggestions in the Paleography of the Basin", Proc. Symp. Upper Mantle Project, No. 8, pp. 261-285, GRB \& NGRI Publ.

10. Veroduzco B, Fairhead J D and Green C M (2004), "New Insights into Magnetic Derivatives for Structural Mapping", The Leading Edge, Vol. 23, No. 2, pp. 116-119. 


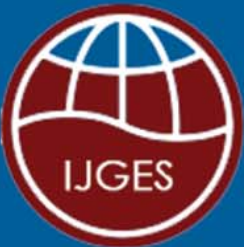

\section{International Journal of Geology and Earth Sciences}

Hyderabad, INDIA. Ph: +91-09441351700, 09059645577

E-mail: info.jiges@gmail.com or editor@ijges.com

Website: www.jiges.com

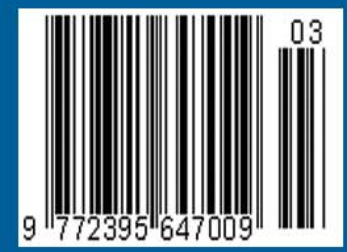

